\title{
Análise Linguística como prática de sala de aula: ensinando/aprendendo verbos no Ensino Fundamental I
}

José Wellisten Abreu de Souza ${ }^{1}$

Universidade Federal da Paraíba josewellisten@hotmail.com

Mônica Mano Trindade Ferraz ${ }^{2}$ Universidade Federal da Paraíba monicatrin@hotmail.com

Thiago Magno de Carvalho Costa ${ }^{3}$ Universidade Federal da Paraíba magnodecarvalho@gmail.com

\section{Resumo}

Este artigo tem por objetivo mostrar como a classe gramatical do verbo é trabalhada em um material didático, elaborado pelo Grupo Educacional Etapa, voltado para o $4^{\circ}$ ano do Ensino Fundamental I. Para tal, realizamos a análise de algumas atividades, com a finalidade de perceber se são atividades de cunho epilinguístico ou reproduções de exercícios metalinguísticos. O texto foi organizado em três seções destinadas: à discussão acerca do ensino de gramática; ao foco na classe dos verbos; e à análise de algumas atividades do material selecionado como corpus, articulada com a proposta de práticas reflexivas como a de Análise Linguística.

Palavras-chave: Ensino. Gramática. Análise Linguística. Verbo.

\footnotetext{
${ }^{1}$ Doutorando em Linguística pelo Programa de Pós-Graduação em Linguística da Universidade Federal da Paraíba (PROLING-UFPB).

${ }^{2}$ Profa. Dra. do Departamento de Letras Clássicas e Vernáculas (DLCV) e do PROLING-UFPB.

${ }^{3}$ Mestre em Linguística pelo PROLING-UFPB.
} 


\section{Abstract}

This paper aims to show how the grammatical category of the verb is presented in a coursebook, prepared by Etapa Educational Group, for the 4th year of Primary Education in Brazil. In order to do that, we make the analysis of some activities in order to understand if the activities comprise epilinguistic features or if they are simply reproductions of meta-linguistic exercises. The text is organized in three sections: the discussion about teaching grammar; the focus on the category of verbs; and the analysis of some activities selected as corpus, combined with the here proposed reflective practice known as Linguistic Analysis.

Keywords: Teaching. Grammar. Linguistic Analysis. Verb.

\section{Considerações iniciais}

Nas últimas décadas, a relevante aplicação da Análise Linguística $(\mathrm{AL})^{4}$ tornou-se uma realidade e uma prática pedagógica bastante próspera, a qual chama atenção de muitos professores de língua materna e pesquisadores que almejam alcançar resultados eficazes dentro e fora da sala de aula. Paralelamente a esse interesse dos docentes por um ensino de língua em uma perspectiva mais reflexiva, há o interesse dos autores de livros didáticos em propor atividades epilinguísticas, o que também parece ser indício de uma mudança de perspectiva: dos tradicionais exercícios gramaticais à prática de AL. Nosso objetivo é, então, mostrar como a classe gramatical do verbo é trabalhada em um material didático, elaborado pelo Grupo Educacional Etapa, voltado para o $4^{\circ}$ ano do ensino fundamental I. Para tal, analisamos o propósito de algumas atividades contidas neste material, atentando para o fato de perceber se são atividades de cunho epilinguístico ou reproduções de exercícios metalinguísticos. A escolha do material a se constituir como corpus de análise é um mero recorte entre tantos outros materiais que foram analisados em uma prática realizada na disciplina de Fundamentos em

\footnotetext{
${ }^{4}$ Tomamos Análise Linguística como o procedimento teórico-metodológico cunhado por Geraldi (1984). Para maiores informações, sugerimos a leitura dos livros O texto em sala de aula (1984) e Portos de Passagem (1997).
} 
Linguística Aplicada, voltada a mestrandos e doutorandos em Linguística 5 .

Para atender o objetivo aqui proposto, este artigo foi organizado em três seções. Inicialmente, contextualizamos a discussão acerca do ensino de gramática, considerando os documentos direcionadores e os estudos propostos pela Linguística nas últimas décadas. Em sequência, focalizamos como conteúdo a classe dos verbos, com base na investigação em duas gramáticas tomadas como exemplo, aplicando a discussão proposta na primeira seção a essa classe gramatical. Finalizando, apresentamos a análise de algumas atividades do material selecionado como corpus e articulamos tal análise com a proposta de práticas reflexivas como a da Análise Linguística.

\section{Considerações sobre a Análise Linguística}

Desde que a Linguística passou a fazer parte do currículo universitário, nos últimos trinta anos, vem se concebendo, ainda que de forma incipiente, a aplicação de uma prática pedagógica a qual conhecemos por Análise Linguística (AL). O termo Análise Linguística foi cunhado por Geraldi (1984) para denominar uma nova perspectiva de reflexão sobre o sistema linguístico e sobre os usos da língua, com vista ao tratamento escolar de fenômenos gramaticais, textuais e discursivos. O que configura um trabalho de AL é a reflexão recorrente e organizada, voltada para a produção de sentidos e/ou para a compreensão mais ampla dos usos e do sistema linguístico.

Relevantemente, a aplicação da AL tem se tornado bastante próspera para aqueles docentes e pesquisadores que assim a fazem em aulas e pesquisas, respectivamente, de língua portuguesa (LP). Entretanto, grande parte dos professores de LP ainda ativos no mercado de trabalho teve, em sua formação, pouco contato com essa prática, até porque muitos deles não foram sequer apresentados à Linguística como ciência da linguagem. Igualmente, ao ingressarem no mercado de trabalho, esses professores se depararam com uma escola

5 Essa disciplina foi ministrada no Programa de Pós-Graduação em Linguística da Universidade Federal da Paraíba. 
enraizada nos métodos tradicionais e com práticas focadas no ensino apenas da metalinguagem, problema agravado pela resistência à mudança, isto é, os docentes que estão em sala de aula há, pelo menos, dez ou quinze anos, desconsideram a teoria do ensino epilinguístico por não se sentirem seguros em aplicar essa nova tendência no ensino de língua materna.

No entanto, percebemos que duas práticas vêm demonstrando uma coexistência em sala de aula: a prática tradicional e o "passo para a mudança". Segundo Mendonça, verifica-se que:

\section{[...] neste momento histórico, do início do $3^{\circ}$ milênio, as práticas de ensino de língua materna do fundamental II (EFII) e do ensino médio (EM), revelam (como sempre revelaram) um mescla de perspectivas: o jeito 'tradicional' de ensinar gramática ainda está presente, ao passo que novas práticas também já são encontradas (MENDONÇA, 2006, p. 200).}

Essa "mescla" de atividades, mencionada pela autora, aparece também nas aulas de ensino fundamental I, até porque os documentos norteadores versam sobre a necessária presença de atividades reflexivas, de cunho epilinguístico, nas aulas de LP.

Para que os alunos adquiram progressivamente uma competência em relação à linguagem, os professores sabem que o ensino de LP deverá ser organizado de forma que eles sejam capazes de "usar os conhecimentos adquiridos por meio da prática de reflexão sobre a língua para expandirem as possibilidades de uso da linguagem e a capacidade de análise crítica" (BRASIL, 1997, p. 33). Os conteúdos de LP em alfabetização, ortografia, pontuação, leitura em voz alta, interpretação de texto, redação e gramática são organizados nos Parâmetros Curriculares Nacionais (PCN) em função do eixo USO $\rightarrow$ REFLEXÃO $\rightarrow$ USO e aparecem na forma de "'Prática de leitura', 'Prática de produção de texto' e 'Análise e reflexão sobre a língua"' (BRASIL, 1997, p. 35), corroborando a proposta de Geraldi (1984; 1997) de que a prática de AL, juntamente com as práticas de leitura e de produção de texto, faz com que o usuário da língua passe a ser um analista da língua, desempenhando dois tipos de reflexão: a epilinguística e a metalinguística. Por isso, os PCN dizem que a AL 
refere-se a dois tipos de atividades de reflexão sobre a língua, mas que se diferenciam nos seus fins:

[...] Nas atividades epilinguísticas a reflexão está voltada para o uso, no próprio interior da atividade linguística em que se realiza [...]. Já as atividades metalinguísticas estão relacionadas a um tipo de análise voltada para a descrição, por meio da categorização e sistematização dos elementos linguísticos (BRASIL, 1997, p. 30).

O ensino da norma padrão não deve ser rechaçado das aulas de língua materna assim como não deve ocorrer uma mera substituição do termo "ensino de gramática" por "reflexão sobre e uso da língua", para que não se torne apenas uma troca de terminologias. O ensino de língua deve ser direcionado de uma forma que o aluno possa compreender os textos produzidos nas diversas situações interacionais, fazendo a relação dos conceitos gramaticais com as práticas de leitura e escrita, resultando, assim, em um aluno que utiliza e reflete bem acerca de sua língua.

Entretanto, há uma demora natural para que o conhecimento produzido na academia seja apropriado pelos profissionais que atuam diretamente na educação básica. Isso se soma ao fato de que nem todas as instituições formadoras estão no mesmo patamar de qualidade, sem falar que os profissionais atuantes no mercado já há algum tempo têm tido pouco, ou nenhum contato com novas formas de pensar e fazer. Por outro lado, positivamente falando, é preciso que fique o registro de que há iniciativas da academia e dos professores em sala de aula para tentar diminuir esse distanciamento entre pesquisa e prática docente, a fim de acabar de vez com essa letargia na condução de um problema que persiste após tantos anos.

Conforme indicado anteriormente, nossa análise tem como foco a classe dos verbos, por isso, na seção seguinte, apresentaremos brevemente como a Gramática Tradicional trata essa classe. Além disso, discutiremos também sobre o que é preconizado nos PCN, visando refletir sobre os aspectos linguísticos relativos ao ensino do verbo no nível fundamental I. 


\section{Apresentação do objeto: o verbo}

O verbo se configura como uma classe de palavras extremamente importante no que tange à construção de textos. Pesquisas no campo da Linguística e inclusive na tradição gramatical reservam espaço para o verbo, seja do ponto de vista da constituição da oração, numa análise sintática, por exemplo, visto que esse elemento é o núcleo do predicado, seja numa perspectiva textual-discursiva.

Em sua gramática, Cegalla define verbo como sendo "[...] uma palavra que exprime ação, estado, fato ou fenômeno" (2008, p. 194). O autor acrescenta que o verbo é "[...] palavra indispensável na organização do período" (CEGALLA, 2008, p. 194), passando, após essa definição a tratar sobre aspectos morfológicos, tais como a flexão de pessoa e número. Em sequência, volta-se para a apresentação dos tempos e modos (cf. pp. 194-201). Reserva-se, vale dizer, uma seção específica para a conjugação do paradigma verbal, tanto dos verbos regulares, como dos irregulares, defectivos e dos auxiliares (cf. pp. 203-252, salvaguardando o espaço dos exercícios, em que pese a "fixação", digamos assim, da apreensão do paradigma de conjugação dos verbos trabalhados).

O professor Bechara apresenta, intitulando de "considerações gerais", a seguinte definição para a classe dos verbos: "entende-se por verbo a unidade de significado categorial que se caracteriza por ser um molde pelo qual organiza o falar seu significado lexical" (2009, p. 209). Apesar do aprofundamento teórico dado por Bechara (2009) em sua gramática, grosso modo, também nela se focaliza, tal como em Cegalla (2008), a caracterização formal das categorias verbais referentes ao nível morfológico, por exemplo, noções relativas às vozes, tempos, modos e aspecto do verbo. Também neste manual amplo espaço é dado à conjugação do paradigma verbal. São iniciados os trabalhos numa seção intitulada "conjugar um verbo", a qual é definida pelo autor: "conjugar um verbo - é dizê-lo, de acordo com um sistema determinado, um paradigma, em todas as suas formas nas diversas pessoas, números, tempos, modos e vozes" (BECHARA, 2009, p. 225) (cf. pp. 225-287, referente ao espaço reservado ao tratamento do paradigma de conjugação verbal na gramática de Bechara). 
Se tomarmos, então, como exemplos as gramáticas de Cegalla (2008) e Bechara (2009) veremos que, do mesmo modo, outros manuais mantêm essa tradição de definição sobre a classe do verbo e depois o amplo enfoque na conjugação do paradigma verbal. Como vimos, 49 páginas da gramática de Cegalla (2008) apresentam todo o paradigma de conjugação verbal, com destaques para verbos regulares, irregulares, abundantes e defectivos (cf. CEGALLA, 2008, p. 203252). Na mesma linha de raciocínio, Bechara (2009), reserva 62 páginas de sua gramática ao trabalho com a conjugação do paradigma verbal $^{6}$. Cabe, então, fazermos o seguinte questionamento: o estudo do verbo, portanto, deve centrar-se, apenas, sobre os aspectos relativos à sua flexão?

Para Travaglia (2011), é necessário estabelecer um estudo cada vez mais amplo e estruturado a respeito do ensino de gramática. De modo mais específico, sobre o ensino do verbo, o mesmo sugerido por Travaglia (2011) aplica-se, posto que são exigidos resultados cada vez em menos tempo, tanto do aluno, se pensarmos, por exemplo, nas provas organizadas pelo Governo Federal, tal como a Provinha Brasil (mantendo o foco no nível fundamental I), como também do professor, que precisa lidar com um complexo trabalho voltado para a estimulação de várias competências e capacidades do aluno, de diversas naturezas: comunicativa, cultural, descritiva, reflexiva, as quais "[...] o aluno precisa desenvolver para sua ação com a língua, para sua atividade linguística" (TRAVAGLIA, 2011, p. 153).

Em sua dissertação, Nunes (2001) dispôs-se a analisar 15 coleções de livros didáticos, objetivando perfazer um diagnóstico acerca do ensino do tópico gramatical verbo no ensino fundamental II de $6^{\circ}$ ao $8^{\circ}$ ano. Nessa pesquisa, a autora observou:

[...] a) [que há] a manutenção sempre dos mesmos tópicos, num leque limitado, dentro do muito que se poderia trabalhar sobre o verbo e b) [que há] uma atitude quase exclusivamente teorizante, com quase nada de atividades

\footnotetext{
${ }^{6}$ Para fins de cômputo, consideramos apenas as páginas em que estiveram presentes a apresentação da conjugação do paradigma verbal e excluímos, portanto, os exercícios em que esse conhecimento formal pode ser exercitado.
} 
Análise Linguística como prática de sala de aula...

que privilegiem o uso e o desenvolvimento da competência comunicativa (NUNES, 2001, p. 8).

A afirmação de Nunes (2001) vai ao encontro do que sugere Travaglia (2011) ao tratar sobre o ensino da classe do verbo tanto nas séries iniciais, como no ensino médio. Para o autor,

[...] o quadro de tópicos e [a] forma de trabalho [com o verbo] não se altera de maneira significativa a não ser em termos de distribuição dos itens pelas séries e talvez em termos da menor ou maior complexidade ou detalhamento do conhecimento sobre o verbo, geralmente apenas o conhecimento elaborado pelos estudos linguísticos tradicionais (TRAVAGLIA, 2011, p. 156).

$\mathrm{O}$ autor conclui que o trabalho feito pelos professores referente ao verbo sempre se volta para a apresentação de um quadro teórico quase exclusivamente centrado na forma do verbo, ou seja, na flexão, na identificação. Segundo o autor, “[...] não se dá atenção ao uso do verbo, suas possibilidades significativas e sua adequação à produção de efeitos de sentido e às situações de uso. [...] Dá-se muita atenção à metalinguagem voltada quase exclusivamente para a morfologia do verbo". (TRAVAGLIA, 2011, p. 158).

Tomando o exposto até aqui, vale propor os seguintes questionamentos: o que versam os PCN? E mais, qual alternativa, então, temos para o trabalho com o verbo?

De acordo com os PCN (1997), o objetivo principal do ensino de Língua Portuguesa é voltar o trabalho para uma análise reflexiva sobre a língua, visando "[...] imprimir maior qualidade ao uso da linguagem” (BRASIL, 1997, p. 31). Desse modo, “[...] as situações didáticas devem, principalmente nos primeiros ciclos, centrar-se na atividade epilinguística, na reflexão sobre a língua em situações de produção e interpretação" (BRASIL, 1997, p. 31) (grifos nossos).

Fica claro, no documento, que o caminho para o aluno tomar consciência sobre a língua e poder, assim, aprimorá-la, visando ao controle da produção linguística, seja na modalidade oral, seja na modalidade escrita, ocorre por meio do uso que se volta para a reflexão e projeta um novo uso. 
Vale ressaltar, ainda, que são apresentados (cf. BRASIL, 1997, p. 33) nove objetivos gerais para o ensino de Língua Portuguesa no nível fundamental. Ainda que não intencionemos aqui discutir cada objetivo, reservando-nos o direito de remeter a eles sem mencioná-los diretamente, é fato que a conjugação verbal não se configura como aspecto ou capacidade universal dentro dos PCN. Esse conhecimento formal coaduna com o interesse de aprendizagem sobre a norma da língua portuguesa, logo, configura-se como extremamente relevante, porém não pode ser o único foco das aulas de português, quando o assunto é a classe de verbos.

Do mesmo modo, nenhum dos sete objetivos gerais referentes ao ensino de Língua Portuguesa nos primeiros ciclos apresentados pelos PCN (cf. Brasil, 1997, p. 68), nos quais se insere o $4^{\circ}$ ano, está voltado apenas à formatização descritiva de uma classe de palavras.

Nesse sentido, para produzirem textos coesos e coerentes, lidando, para tanto, com gêneros textuais diversos, os alunos não podem apenas ser expostos, no trabalho com o verbo, à descrição do paradigma verbal. Essa deve ser uma parte com a qual a reflexão sobre a língua se soma e projetam-se os objetivos comunicativos e de uso efetivo da língua. É assim, portanto, que do Uso $\rightarrow$ Reflexão $\rightarrow$ Uso chega-se ao movimento metodológico da Ação $\rightarrow$ Reflexão $\rightarrow$ Ação (cf. BRASIL, 1997, p. 36-37).

Perini assevera que "quando conhecemos o verbo de uma oração - isto é, seu significado e os complementos com que ele coocorre - podemos determinar boa parte da estrutura das orações em que ele figura" (2010, p. 135). Vale atentar para o fato de que, na proposta de sua gramática, Perini (2010) entende que a compreensão do que é um verbo passa pelo entendimento, grosso modo, da identificação dele como elemento constituinte da oração, mas, além disso, deve ser observada a significação decorrente do uso desse elemento na construção do todo.

Em outras palavras, a reflexão sobre a língua a que vimos fazendo referência diz respeito à soma de uma perspectiva metalinguística com uma epilinguística. Ao fazer desse o trabalho com o verbo, e com as demais classes de palavras, não estaremos falando, "[...] portanto, [...] meramente de especulações teóricas, mas da descrição de um conhecimento que existe na memória de todos os 
falantes do português" (PERINI, 2010, p. 136), o qual precisa ser acionado para que a aprendizagem se efetive.

Nesta seção, tivemos como interesse apresentar o objeto sobre o qual nos detemos e sobre o qual nos propomos analisar neste artigo, ou seja, a classe do verbo. Verificamos, em linhas gerais, como o trabalho com essa classe gramatical vem sendo feito ao longo dos anos, culminando, em muitas das vezes, com o fracasso das aulas de Português, que sempre se apresentam maçantes e pouco relacionadas com a realidade de usos da língua. Detivemo-nos, ainda, nos trabalhos de alguns autores e, principalmente, nos PCN, visando extrair a forma como deve ser trabalhada tal classe gramatical no ensino de língua portuguesa. Na próxima seção, apresentaremos atividades presentes no material didático elaborado pelo Grupo Educacional Etapa, voltado para $04^{\circ}$ ano do ensino fundamental I, visando observar se são atividades de cunho epilinguístico ou reproduções de exercícios metalinguísticos.

\section{$4 \mathrm{O}$ verbo no ensino fundamental I: análise do corpus}

O material didático do Sistema Etapa:

foi concebido para que cada aluno desenvolva, ao máximo, o potencial de competências e habilidades que traz dentro de si. O Sistema Etapa criou e vem adotando, com exclusividade, o ensino em Espiral Crescente. Esse método distribui os conteúdos à medida que as séries avançam. Dentro de uma linha de coerência, ele permite que o aluno retome conceitos de forma atualizada e comparativa. $O$ benefício do ensino em espiral crescente é a garantia de sedimentação do conhecimento ${ }^{7}$.

Os alunos do ensino fundamental $\mathrm{I}$, o qual compreende o $4^{\circ}$ ano, recebem oito módulos (apostilas) e cada módulo, similarmente, divide os conteúdos na seguinte ordem: (a) Matemática; (b) Português;

${ }^{7}$ Disponível em <http://www.sistemaetapa.com.br/>. Acesso: 17 set 2013. 
(c) Ciências; (d) Geografia/História. O módulo de Língua Inglesa é recebido separadamente uma única vez e utilizado durante todo o ano.

Para o presente trabalho, foram contabilizadas atividades do Módulo 1 ao Módulo 8 referentes à disciplina de Língua Portuguesa. Salientamos, porém, que foram registradas atividades sobre o estudo do verbo apenas nos Módulos 1, 2, 3 e 5.

Com o intuito de facilitar a identificação, resolvemos classificar as atividades em três categorias, a citar: (i) grupo I atividades de conjugação do paradigma verbal, incluindo aquelas que propõem tabelas para a conjugação verbal em diferentes tempos; (ii) grupo II - atividades de identificação dos verbos nos textos e/ou em frases do texto; (iii) grupo III - atividades com a proposta de classificação das três terminações verbais; e (iv) grupo IV - atividades com a proposta de reescrita de trechos do texto ou de frases modificando o tempo verbal.

Portanto, para cada grupo, após a contabilidade feita, as atividades ficaram distribuídas, quantitativamente, da seguinte forma:

Quadro 1: Distribuição das atividades por módulos

\begin{tabular}{|c|c|c|c|c|}
\hline Categoria & Módulo & $\begin{array}{l}\text { Quantidade } \\
\text { por Módulo }\end{array}$ & $\begin{array}{c}\text { Quantidade } \\
\text { Total }\end{array}$ & Observação \\
\hline \multirow{4}{*}{ 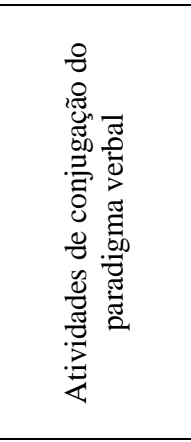 } & 1 & 6 & & \multirow{4}{*}{$\begin{array}{l}\text { No módulo 1, são } \\
\text { propostas duas atividades } \\
\text { com tabelas para realizar } \\
\text { a conjugação verbal. Já } \\
\text { no módulo 5, este tipo de } \\
\text { atividade aparece três } \\
\text { vezes. As outras } \\
\text { atividades possuem } \\
\text { diversos formatos. } \\
\text { Aparecem, inclusive duas } \\
\text { cruzadinhas e um jogo } \\
\text { (caça ao tesouro). } \\
\end{array}$} \\
\hline & 2 & 2 & & \\
\hline & 3 & 3 & & \\
\hline & 5 & 7 & 18 & \\
\hline \multirow{4}{*}{ 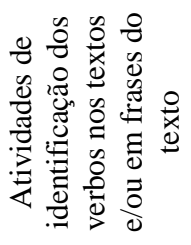 } & 1 & 1 & \multirow{4}{*}{6} & \\
\hline & 2 & 1 & & \\
\hline & 3 & 0 & & \\
\hline & 5 & 4 & & \\
\hline
\end{tabular}


Análise Linguística como prática de sala de aula...

\begin{tabular}{|c|c|c|c|c|}
\hline Categoria & Módulo & $\begin{array}{l}\text { Quantidade } \\
\text { por Módulo }\end{array}$ & $\begin{array}{c}\text { Quantidade } \\
\text { Total }\end{array}$ & Observaçãa \\
\hline \multirow{4}{*}{ 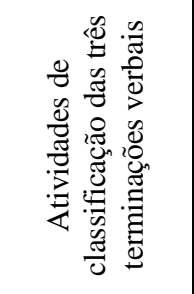 } & 1 & 1 & \multirow{4}{*}{3} & \\
\hline & 2 & 0 & & \\
\hline & 3 & 1 & & \\
\hline & 5 & 1 & & \\
\hline \multirow{4}{*}{ 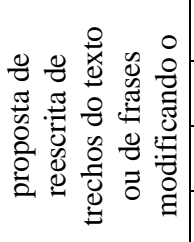 } & 1 & 0 & \multirow{4}{*}{3} & \\
\hline & 2 & 0 & & \\
\hline & 3 & 0 & & \\
\hline & 5 & 3 & & \\
\hline
\end{tabular}

Fonte: Elaborado pelos autores

\subsection{Atividades de conjugação do paradigma verbal}

Vejamos a questão 25b presente na página 46 do módulo 5:

b) Conjugue o verbo combinar no presente, no pretérito perfeito e no futuro do presente.

\section{Presente Pretérita perbeita Fulura da presente}

\section{eu \\ tu \\ ele \\ nós \\ vós \\ eles}

Figura 1: Questão 25b, Módulo 5

Fonte: Sistema Etapa (2013c, p. 46) 
Um questionamento pertinente de ser levantado a priori, principalmente por estarmos lidando com o ensino de LP no nível fundamental I, é: há diferença entre alfabetização e letramento?

De acordo com Travaglia (2013), o qual reflete sobre as considerações de Soares (2008), temos:

[...] a alfabetização é entendida hoje como o domínio do sistema alfabético e ortográfico, a aquisição do sistema convencional da escrita. Já o letramento é entendido como $o$ desenvolvimento de habilidades, comportamentos $e$ práticas de uso competente do sistema convencional da escrita na produção e compreensão de textos dentro de práticas sociais em que a leitura e a escrita estejam envolvidas (TRAVAGLIA, 2013, p. 11) [grifos do autor].

Uma assunção que pode ser levantada, então, diz respeito ao modo como preparamos nossos alunos para o domínio no uso da língua e ao espaço destinado aos tipos de atividades. No manual analisado, atividades similares à 25 b ocorrem no decorrer de oito módulos e representam três vezes o espaço direcionado às atividades de cunho analítico-reflexivo.

Atividades de natureza reflexiva devem ser entendidas, assim como sugere Travaglia $(2009 ; 2013)$ como o trabalho com os conhecimentos linguísticos, mais especificamente, uma gramática reflexiva. Para o autor, "a gramática reflexiva é um tipo de atividade que trabalha essencialmente com a significação dos recursos linguísticos (semântica) e sua utilização em situações específicas e concretas de interação comunicativa (pragmática)" (TRAVAGLIA, 2013, p. 29) [grifos do autor]. Nesse mesmo sentido, vale ressaltar que o que configura um trabalho de $\mathrm{AL}$ é a reflexão recorrente e organizada, voltada para a produção de sentidos e/ou para a compreensão mais ampla dos usos e do sistema linguístico, com o fím de contribuir para a formação de leitores-escritores de gêneros diversos, aptos a participarem de eventos de letramento com autonomia e eficiência. A postura a ser assumida é a de que as aulas de Língua Portuguesa (que se pretendam reflexivas) devem envolver, além do nível morfossintático, os níveis semântico e pragmático. 
Se pensarmos bem, é no ensino fundamental I que reside a maior importância da educação básica. É ele o alicerce no qual se configura (ou não, infelizmente) a relação do aluno com o estudo formal da Língua Portuguesa, permitindo-lhe acesso mais aprofundado à língua materna no decorrer da vida escolar, servindo-lhe de base até para uma futura vivência no ensino superior. Dito de outro modo: a) a falta de exploração de atividades reflexivas, nas quais tanto a decodificação e a memorização da forma, voltadas à alfabetização do indivíduo, e b) a falta de exercitação de atividades que envolvam o desenvolvimento de competências linguísticas de uso, voltadas aos múltiplos letramentos, pode significar evasão escolar, exclusão do indivíduo de certas práticas sociais letradas, impossibilidade de interação com certos gêneros textuais/discursivos, por fỉm, negação de um direito: a formação de um cidadão competente e usuário, proficiente, de sua língua materna.

A discussão a que vimos fazendo referência desde o início deste artigo levou alguns pesquisadores a teorizarem sobre como viabilizar a reflexão nas aulas de LP. Esses estudos se mostram latentes desde os últimos quarenta anos e foram eles que influenciaram a produção dos Parâmetros Curriculares Nacionais.

No artigo "Unidades básicas do ensino de português", inaugural no que tange à proposição do termo AL, Geraldi (1984) diz que "a única coisa que [lhe] parece essencial na prática de análise linguística é a substituição do trabalho com metalinguagem pelo trabalho produtivo de correção e autocorreção de textos produzidos pelos próprios alunos" (1984, p. 68) [grifos do autor]. Neste artigo, o autor está preocupado em apresentar sugestões de atividades voltadas para as práticas de leitura e produção de texto. Para tanto, ele considera a AL como um dos eixos (associado aos anteriores) básicos do ensino de língua materna.

Esta percepção apresentada por Geraldi (1984) entende que o professor deve ensinar a gramática da língua juntamente com os usos que se dá para a língua (isso é fazer AL). Logo, uma atividade como 25b, cujo objetivo é exercitar um nível de conhecimento linguístico do aluno, a saber, o metalinguístico, especificamente tratando da conjugação do verbo combinar no presente, no pretérito perfeito e no futuro do presente, deve ser um dos passos e não o único (atrevemonos a dizer: não o mais explorado) quando o foco é o ensino da classe 
dos verbos nas séries iniciais. É imprescindível, indo além, levar o aluno a entender as nuances de sentido que estabelecem a diferença entre o presente, o passado e o futuro.

Dado o fato de o nível ser elementar, posto que lidamos com um material voltado para o $4^{\circ}$ ano do ensino fundamental I, inferências que possam levar o aluno a diferir enunciados como:

\section{I) Eu jogo bola todo dia.}

II) Eu joguei bola ontem com o André e III) Jogarei bola com a Ana quando eu chegar da casa da vovó

cuja mudança de tempo da ação se dá pela mudança do paradigma verbal, somada a inserção de elementos circunstanciais temporais, tal como advérbios, por exemplo, são de suma importância para que se chegue a outro nível de desenvolvimento da competência linguística dos alunos.

A construção desse conhecimento basal é premissa fundamental para o avanço linguístico-reflexivo dos alunos diante dos fatos da língua. Isso se dá pari-passu como se, juntamente com o aluno, o professor elevasse o grau de complexidade a cada novo dia de aula. Não se deve atropelar o desenvolvimento cognitivo, mas assumimos a posição de que o enfoque amplamente destinado nos manuais didáticos à metalinguagem e à memorização do paradigma de conjugação verbal é, além de limitador, aquém da necessidade de exploração da realidade de uso da língua.

$\mathrm{O}$ que queremos dizer é que nossas aulas de português (pelo menos as que se pretendem contributivas) devem englobar tanto a análise da estrutura como a interação social com propósitos comunicativos sejam os textos orais ou escritos.

Da conjugação de um verbo, a uma oração, a um período, a um texto, e assim por diante, levaremos nossos alunos a identificação, a interpretação, a análise e a reflexão sobre os recursos linguísticos de sua língua materna, (seja, por questão de escopo desse artigo, o verbo, ou qualquer outra classe gramatical).

Observemos, agora, a questão 72 presente na página 62 do módulo 5: 
72 Caça ao tesouro.

Seguindo as setas, preencha os quadrinhos com os verbos que seu professor vai indicar. Se você errar, faça um $X$ na casa e retire uma moeda do baú. Vamos descobrir quem ganhou o tesouro?

Legenda: $\quad \mathbf{p} p=$ pretérito perfeito $\quad \mathbf{p} \mathbf{i}=$ pretérito imperfeito $\quad \mathbf{p}=$ presente $\mathrm{fp}=$ futuro do presente $\mathrm{fpp}=$ futuro do pretérito

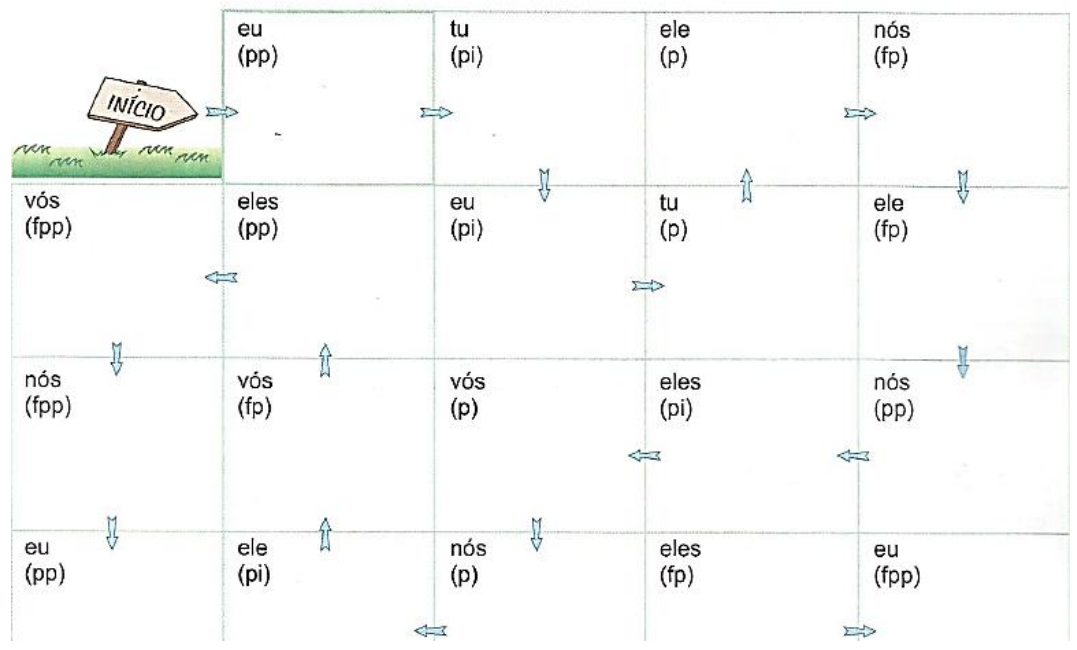

Figura 2: Questão 72, Módulo5

Fonte: Sistema Etapa (2013c, p. 62)

Dissemos anteriormente que a postura a ser assumida nas aulas de Língua Portuguesa cujo foco seja a exploração de atividades reflexivas passa pelo envolvimento tanto de aspectos relativos ao nível morfossintático, como aos níveis semântico e pragmático. Tal tese parece coadunar com o pensamento apresentado Travaglia (2013), a saber:

Se o usuário competente da língua deve saber usar seus recursos para produzir os efeitos de sentido pretendidos $e$ compreender estes efeitos em textos recebidos, consequentemente o ensino deve focar no $(s)$ sentido $(s)$ que um recurso da língua é capaz de mobilizar em um texto. [Em outras palavras,] [...] para atingir [o] objetivo de 
desenvolver a competência comunicativa é fundamental trabalhar e desenvolver nos alunos as habilidades de uso da língua e, também, seu conhecimento das contribuições dos recursos linguísticos para o sentido do que se diz (TRAVAGLIA, 2013, pp. 27-28).

Nesses termos, a questão 72 ora analisada também focaliza apenas um dos níveis de trabalho com a língua tal como a questão $25 \mathrm{~b}$ anteriormente observada. Ainda que tenha se explorado o lúdico, base da questão 72, justamente pelo fato de a tentativa ser envolver os alunos com um jogo, o fim é, novamente, a exploração, apenas, da conjugação do paradigma verbal, desconsiderando contexto de uso, um gênero textual no qual tais recursos linguísticos pudessem ser vistos em funcionamento. Enfim, não se percebe o trabalho quanto à contribuição dos verbos como recursos da língua voltados para o estabelecimento do sentido de um texto.

\subsection{Atividades de identificação dos verbos nos textos e/ou em frases do texto}

Atentemos para a questão na página 55 do módulo 2 (Fig. 3). Travaglia (2013) afirma que

[...] o conhecimento linguístico não é, como muitos pensam, apenas saber teoria gramatical/linguística e terminologia para analisar elementos da língua. Evidentemente este conhecimento teórico vai acontecer em conjunto com todas as atividades que [o professor] vai desenvolver para que o aluno: a) adquira a variedade escrita da língua, uma vez que ele [já] domina uma variedade oral familiar quando chega à escola e b) alcance progressivamente o domínio e a capacidade de uso de um número cada vez maior de recursos da língua, tornando-se um usuário da língua progressivamente mais competente (TRAVAGLIA, 2013, p. 12). 


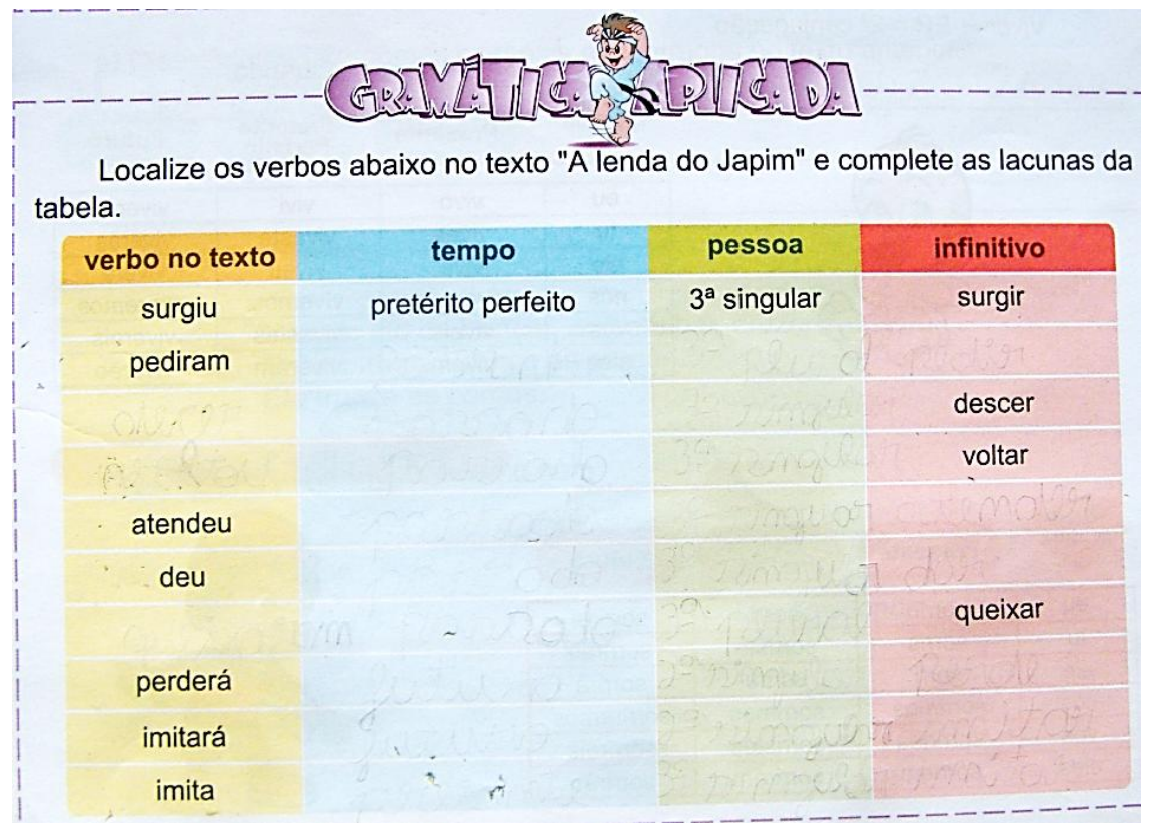

Figura 3: Questão da seção Gramática Aplicada, Módulo 2 Fonte: Sistema Etapa (2013b, p. 55)

Logo, repercutindo o que sugere Travaglia (2013), faz-se necessário entender que é insuficiente a promoção de uma metodologia de ensino que focaliza apenas questões de classificação de elementos da língua via nomenclatura. Não podemos prescindir da importância da dimensão do uso que se dá aos elementos da língua e, mais do que isso, não podemos prescindir à importância dos efeitos de sentido que emergem das ações de uso da língua(gem).

Chama a atenção o fato de ela estar associada a uma seção do manual didático intitulada "Gramática Aplicada". O que se espera ao ver o título de tal seção é que os conhecimentos teóricos paulatinamente abordados durante o ano letivo a respeito do assunto dos verbos sejam (enfim) trabalhados contextualmente, aplicados a uma atividade de natureza epilinguística. No entanto, a mudança de paradigma que se dá é apenas na nomenclatura.

Uma abordagem reflexiva não é um avanço apenas porque não mais se deve chamar conjugação por tal nome e se substituir, por 
exemplo, o termo por outro da moda e que seja aceito na comunidade linguística. $O$ avanço é justamente nas práticas resultantes. $O$ que vemos nessa questão, ao contrário, é novamente o interesse de que o aluno demonstre uma memorização a respeito do modelo de flexão verbal quanto ao tempo, à pessoa e ao modo. O texto vira pano de fundo, ou como já foi amplamente criticado por outros autores, tornase pretexto para atividades de cunho metalinguístico (tão somente), sem que haja, além da exploração deste aspecto, o avanço quanto ao conhecimento linguístico reflexivo, por parte do aluno, de sua língua materna.

Solicita-se, como é possível observar, a identificação dos verbos no texto através do comando: "Localize os verbos abaixo no texto 'A lenda do Japim' e complete as lacunas da tabela", mas não é solicitado dos alunos verificar alguma alteração de sentido, por exemplo, entre os verbos imita/imitará, flexões do verbo imitar utilizadas em um dado contexto de uso de um gênero textual.

Reiteramos, então, que a abordagem semântico-pragmática é essencial às práticas de sala de aula, pois os aspectos da significação são essenciais às habilidades de compreensão, produção e análise linguística. Trabalhar com inferências é trabalhar com a compreensão dos implícitos, em vários níveis. Abordar tais conceitos se faz necessário no decorrer do processo de leitura, pois são eles (entre outros) que determinam a construção do conhecimento linguístico do aluno. Perde-se muito ao voltarmos nossas atenções, nas aulas, apenas para o tratamento de um dos níveis da língua. Perde-se muito mais, quando o foco de um manual didático é amplamente detido a um único nível, frise-se, o metalinguístico, e quando, passivamente, como professores, não assumimos uma postura contrária ao posto, como se o livro fosse uma regra e não uma ferramenta para os objetivos que precisamos alcançar com nossos alunos.

\subsection{Atividades de classificação das três terminações verbais}

Voltemos agora nossas atenções para a questão 55 presente na página 63 do módulo 1: 
55 No texto "Números traiçoeiros" você encontra uma série de verbos, como, por exemplo, é (verbo ser), pensava (verbo pensar) e dirigia (verbo dirigir). $O$ verbo ser é complicado porque é irregular. Vamos nos preocupar com os verbos regulares. Os verbos terminam em ar, er ou ir na forma que chamaremos infinitivo.

No trecho

"Marcelo entrou na casa de seu primo, mal cumprimentou os tios, dirigiu-se a César e disse:

- Você quer a minha coleção de cards? Então aceite meu desafio."

destaque os verbos que, no infinitivo, terminam por:
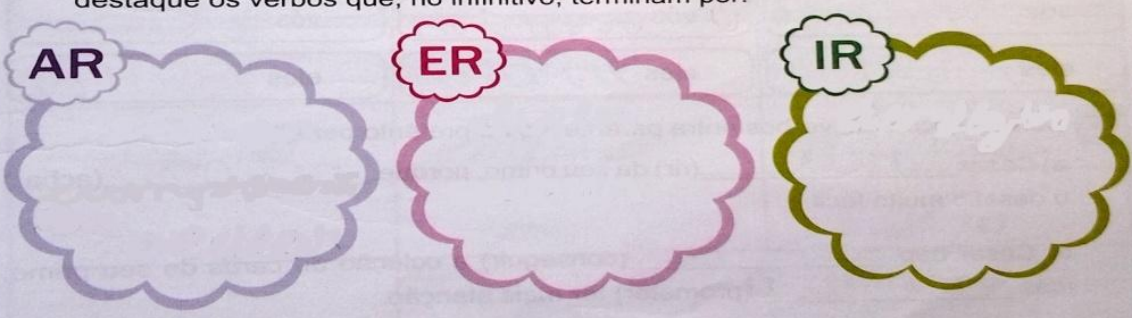

Obs.: o verbo pôr e seus compostos (compor, repor, dispor, etc.) pertencem à segunda conjugação. Antigamente escrevia-se poer.

Figura 4: Questão 55, Módulo 1

Fonte: Sistema Etapa (2013, p. 63)

$\mathrm{Na}$ questão 55, percebemos o interesse do autor do LD em trabalhar com uma característica formal que distingue os verbos, justamente os três tipos de conjugação possível, a saber: a dos verbos terminados em -ar, a dos terminados em -er e a dos terminados em -ir. Para tal, é solicitado, na questão, que os alunos analisem um período, identifiquem os verbos, e coloquem-nos em cada balão correspondente a um tipo de conjugação verbal.

Vemos, nessa questão, a exploração de uma consciência reflexiva por parte dos alunos. Para a resolução desta questão, será preciso que o aluno lance mão, primeiro, de um conhecimento lexical, haja vista ser necessário identificar verbos já armazenados por ele em seu acervo mental. Depois, vendo o verbo conjugado, é necessário que o aluno recupere sua forma no infinitivo, julgue se esta é de $1^{a}, 2^{a}$ ou $3^{a}$ conjugação para que assim, por fim, aloque cada verbo adequadamente em um dos balões indicados. Talvez, nessa questão, não resida um trabalho com um gênero textual nem com aspectos relativos ao sentido no uso de um dado verbo, entretanto se faz necessário esse trabalho 
José Wellisten; Mônica Ferraz; Thiago Costa

basal no desenvolvimento linguístico do aluno. Para que o aluno, ao ler o trecho Marcelo entrou na casa do seu primo, consiga identificar qual dentre as palavras presentes na oração é um verbo, recuperar qual seria sua forma nominal no infinitivo e concluir que entrou antes de sofrer flexão é entrar, verbo de primeira conjugação, demanda-se reflexão sobre a língua. Ressaltamos, porém, a característica basal dessa reflexão, ou seja, ela serve de alicerce para outras de natureza mais complexa e que são, talvez, mais necessárias de serem trabalhadas com o aluno, por terem papel importante, por exemplo, na leitura de textos, cujo jogo com o sentido de um elemento linguístico direciona a interpretação a ser inferida.

\subsection{Atividades com a proposta de reescrita de trechos do texto ou de frases modificando o tempo verbal}

A seguir, analisaremos a questão relativa à seção Gramática Aplicada presente na página 60 do módulo 5:

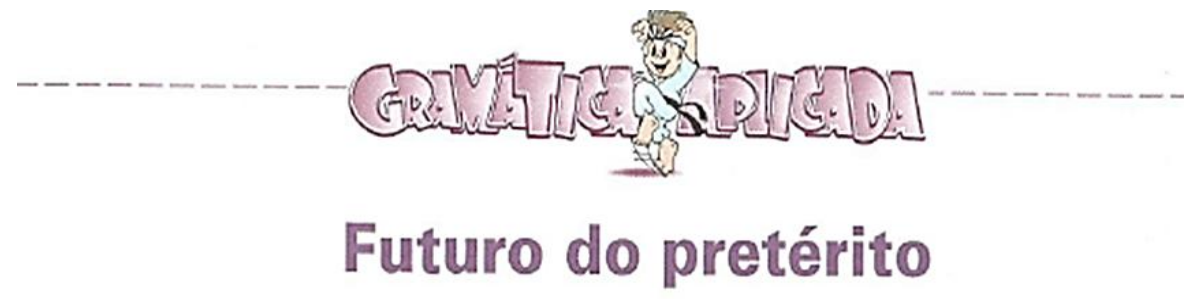

O texto "Se eu fosse..." contém uma série de verbos, tais como: correria, , todos terminados por ria.

Assim, pode-se dizer que "se eu fosse..." aconteceria alguma coisa.

Os verbos enunciados acima estão no futuro do pretérito e indicam uma condição para que algo aconteça.

Figura 5: Questão da seção Gramática Aplicada, Módulo 5

Fonte: Sistema Etapa (2013c, p. 60) 
Uma seção intitulada como Gramática Aplicada apresenta-se como o momento em que se espera grande intervenção do professor, no sentido de ampliar a atividade, buscando a perspectiva do uso e da reflexão. Não se trata apenas de trabalhar o aspecto morfológico, isto é, a flexão do verbo no tempo futuro do pretérito (terminando em -ria), conhecimento que, obviamente, é fundamental para a apropriação do sistema linguístico. Trata-se de também possibilitar aos alunos que compreendam as situações de uso desse tempo verbal e o sentido que confere aos enunciados. Assim, é necessário que se criem situações de diálogo, provocando a construção de enunciados como "se eu fosse X, eu faria Y", e que se discuta o sentido dessas construções quando comparadas às outras formadas por outro tempo verbal. Nesse exemplo, é necessário que se compreenda a diferença entre as construções "se eu fosse" e "se eu for", mostrando as complementações que variam entre futuro do pretérito e futuro do presente. Enfim, mesmo sendo relevante o exercício de buscar, no texto, os verbos conjugados no futuro do pretérito, o que conferiu à atividade o rótulo de gramática aplicada, ainda se faz necessário ampliar e buscar as situações de uso real da língua.

\section{Considerações finais}

Em consequência das mudanças que as orientações oficiais vêm preconizando, tal como discutimos anteriormente, em especial a partir da publicação dos PCN em 1997, efetiva-se o papel de documentos que visam guiar a produção dos LD no Brasil. Como sabemos, é no decênio de 1990 que o MEC passa a sistematizar as discussões sobre a qualidade do LD. Ainda que, historicamente, esteja claro que o LD é um instrumento que acompanha os professores no ensino desde há muito tempo, algo que, por exemplo, os jesuítas já faziam, não havia, até 1993, uma preocupação acerca do controle de qualidade dos livros. É justamente nesse ano que se dá a criação de uma comissão de especialistas responsável por avaliar a qualidade dos LD e estabelecer critérios gerais para a avaliação das novas aquisições. Essa ação do Governo Federal configura-se como um projeto pedagógico difundido por meio dos Parâmetros Curriculares Nacionais, culminando na confecção dos Guias do Livro Didático, 
vinculados ao Programa Nacional do Livro Didático (PNLD), iniciado, timidamente em 1985, vindo a se fortalecer a partir dos anos $1990^{8}$.

No PNLD 2013 direcionado ao ensino fundamental - séries iniciais -, mais especificamente na segunda etapa — que, no âmbito do PNLD, compreende o quarto e o quinto anos — é dito que uma das práticas a ser assumida pelo autor do livro, em que se pese isso, inclusive, na escolha do manual didático, diz respeito à presença de estratégias, a serem partilhadas com o professor, que levem "[...] o aluno à consolidação do duplo processo iniciado na etapa anterior [relativa à primeira etapa, intitulada Letramento e Alfabetização iniciais], desenvolvendo tanto sua proficiência em leitura e escrita quanto sua capacidade de refletir sobre a língua e a linguagem" (BRASIL, 2012, p. 11). Em outras palavras, subjaz no documento a orientação de que é preciso estimular a consciência reflexiva do discente por meio de práticas de análise e reflexão sobre a língua, seja para a (re)construção dos sentidos de textos, seja para a compreensão do funcionamento da língua e da linguagem, dentro dos limites que o nível estabelece.

Apenas para dimensionarmos o que aparece como orientações no PNLD 2013, vejamos um dentre os cinco objetivos centrais para o ensino de língua materna durante todo o ensino fundamental. É considerado central: “A prática de análise e de reflexão sobre a língua e a linguagem, na medida em que se fizer necessária ao desenvolvimento da linguagem oral e escrita, em compreensão e produção de textos" (BRASIL, 2012, p. 11).

É imprescindível, portanto, que constem, nos livros, exercícios, trabalhos com gêneros textuais, atividades de leitura que se relacionem com as práticas de reflexão sobre a língua nos termos do que já vimos expondo anteriormente. Nas palavras presentes no PNLD 2013, temos:

Assim, as práticas de uso da linguagem, isto é, as atividades de leitura e compreensão de textos, de produção escrita e de produção e compreensão oral, em situações contextualizadas de uso, devem ser prioritárias nas

\footnotetext{
${ }^{8}$ Para mais informações, consulte: <http://www.fnde.gov.br/programas/livrodidatico/livro-didatico-historico>.
} 
propostas dos livros didáticos. As práticas de reflexão sobre a língua e a linguagem, assim como a construção correlata de conhecimentos linguísticos e a descrição gramatical, na medida em que se façam necessárias e significativas para a (re)construção dos sentidos dos textos, devem se exercer sobre os textos e discursos (BRASIL, 2012, pp. 11-12).

Por fim, acreditamos que a compreensão a ser exigida dos alunos face às questões relativas à classe gramatical do verbo deve congregar tanto aspectos de natureza metalinguística quanto aspectos de natureza epilinguística. Apenas dessa forma é que a almejada reflexão diante dos fatos da língua, conforme preconizado nos PCN e na AL, será atendida. Além disso, assumimos que o professor deve ser o responsável pelo equilíbrio entre tais práticas, o que implica conhecer as propostas metodológicas ao ensino da língua materna, assim como o lugar da gramática nessas propostas, e possuir um olhar atento aos materiais com os quais lida, buscando, a partir das atividades já postas, a complementação e a ampliação para o desenvolvimento das habilidades de uso e reflexão.

\section{Referências}

BRASIL. Parâmetros curriculares nacionais: língua portuguesa. Secretaria de Educação Fundamental. Brasília: Ministério da Educação, Secretaria da Educação Fundamental, 1997.

- Guia de livros didáticos PNLD 2013: letramento e alfabetização e língua portuguesa. Brasília: Ministério da Educação, Secretaria de Educação Básica, 2012.

BECHARA, Evanildo. Moderna gramática portuguesa. 37 ed. Rio de Janeiro: Nova Fronteira, 2009.

BEZERRA, Maria Auxiliadora; REINALDO, Maria Augusta. Análise linguística como eixo do ensino de Língua Portuguesa. In:

Análise linguística: afinal a que se refere? São Paulo: Cortez, 2013. p.33-61. 
CEGALlA, Domingos P. Novíssima gramática da língua portuguesa. 48 ed. rev. São Paulo: Companhia Editora Nacional, 2008.

GERALDI, João Wanderley. O texto na sala de aula: leitura e produção. 3. ed. Cascavel: Assoeste, 1984.

MENDONÇA, Márcia. Análise linguística no ensino médio: um novo olhar, um outro objeto. In: BUNZEN, Clécio; MENDONÇA, Márcia (Orgs.). Português no ensino médio e formação do professor. São Paulo: Parábola Editorial, 2006. p.199-226.

NUNES, Gisele P. O ensino de gramática nas escolas de ensino fundamental: a questão do verbo. Dissertação (Mestrado em Linguística) - Instituto de Letras e Linguística, Universidade Federal de Uberlândia, 2001.

PERINI, Mário A. Gramática do português brasileiro. São Paulo: Parábola Editorial, 2010.

SISTEMA ETAPA. Apostila para Ensino Fundamental I: $4^{\circ}$ ano. Módulo 1. São Paulo: Núcleo, 2013.

. Apostila para Ensino Fundamental I: $4^{\circ}$ ano. Módulo 2. São Paulo, Núcleo, 2013.

. Apostila para Ensino Fundamental I: $4^{\circ}$ ano. Módulo 5. São Paulo, Núcleo, 2013.

TRAVAGLIA, Luiz Carlos. Na trilha da gramática: conhecimento linguístico na alfabetização e letramento. 1. ed. São Paulo: Cortez, 2013.

. Gramática: ensino plural. 5. ed. São Paulo: Cortez, 2011.

- Gramática e interação: uma proposta para o ensino de gramática. 14. ed. São Paulo: Cortez, 2009. 
Análise Linguística como prática de sala de aula...

Recebido em: 19/07/2015

Aceito em: 10/10/2015

Title: Linguistic Analysis as class practice: teaching/learning verbs in the elementary school 